$\Phi=\Phi$

\title{
Description of a quality improvement training programme for health professionals in the ministry of health and social services in Namibia
}

\author{
Julia Paul Nangombe ${ }^{1 *}$, Amukugo Hans Justus ${ }^{2}$ \\ ${ }^{I}$ Quality Assurances and Quality Improvement. Office of Vice President, Veterans Affairs, Republic of Namibia \\ ${ }^{2}$ Lecturers, School of Nursing and School of Public Health, Faculty of Health Sciences University of Namibia \\ *Corresponding author E-mail: julianangombe@yahoo.com
}

\begin{abstract}
The aim of this paper is to describe the quality improvement training programme for health professionals in the Ministry of Health and Social Services in Namibia. The Practice Oriented Theory of Dickoff (1968) was used as practical guidelines to develop the conceptual framework. This framework was employed during the research and the educational programme development process. During the research process, the agent was the researcher; recipients (Managers/leadership and health professionals); the context (MoHSS head office and healthcare facilities); dynamics (findings for objective one and two); Procedure (research process) and terminus (foundations for development of educational programme).

For the educational programme developing process, agent (quality specialist), recipients (health professional), context (health facilities), procedure (training programme for health professionals), dynamics, (challenges hampering successful implementation of the programme) and the terminus (knowledge, skills and abilities acquired through the training programme). During the development of the quality improvement training programme, two main theories were adapted. The most prominent one was a model by Meyer and Van Niekerk (2008), which was adapted to guide the process of developing the training programme. Kolb's experiential learning theory was used to explain the learning process and styles of developing knowledge through experiences.

The content of the training programme was derived from five main themes, 17 sub-themes and the conceptual framework based on the situation analysis about challenges faced by the health care facilities. The five themes were lack of implementation of policies and guidelines; inadequate resources; lack of interpersonal relationships; inadequate understanding of quality assurance and quality improvement; and inadequate research to provide evidence-based information during treatment and patient care.
\end{abstract}

The educational programme consisted of the purpose / aim, objectives, structure / design, facilitation process, implementation process, and evaluation of the programme.

Keywords: Description; Quality Improvement; Training Programme; Health Professionals.

\section{Introduction}

The Ministry of Health and Social Services (MoHSS) in Namibia has prioritised the training of health professionals; however, 37\% of health professionals indicate that no formal programme is in place to empower health professionals to improve quality health care delivery at the health care facilities (MoHSS, 2014). Health care facilities can no longer remain static given the increasing demand and public pressure to improve quality health care (MoHSS, 2013). The National Quality Management System Report has pointed at the burden of staff shortage as one of the reasons for transferring some functions to inexperienced health personnel, at least one person (15.4\%) out of the staff complement at a health care facility, since the remaining staff members had to attend to long queues with no time to focus on quality (MoHSS, 2014). Most health care systems have existing quality assurance (QA) standards but often these standards are not properly followed to respond to the needs of the clients (WHO, 2000). On the other hand, absence of rewards and a recognition system seem to contribute to poor quality health care delivery by the MoHSS. At the time of this study, there were no effective strategies to retain or attract health professionals to the public health sector. More than sixty per cent $(62.5 \%)$ of staff members at the assessed health care facilities indicated that staff recognition was only informally done by immediate supervisors but no incentive strategies existed to recognise good performance with the purpose of improving the quality of health care. The result of "...poor performance is few staff or staff not providing care according to standards and not being responsive to the needs of the community and patients" (WHO, 2006).

In Namibia, QA and QI activities depend to a large extent on effective management of resources (human, physical infrastructure, and finance). In addition, the components of quality health care and services are largely dependent on accessible health care and services to those people who need it. Offei, Sagoe, Owusu Acheaw, Doyle and Haran (2004) explain that a number of quality health care components influence the access and provision of 
health care and services. For example, access to quality health care can be used as an indicator for the ability of individuals to obtain health care and services.

Technical competencies are another aspect that empowers health professionals with adequate knowledge, skills, and aptitudes to provide excellent and professional care and services. Secondly, it facilitates the functions proficiently according to the standards of quality health care services. Hence, health professionals need to be empowered in order to provide the type of care that produces positive change in the patients' health or quality of life.

The Ghanaian Ministry of Health has prioritised a similar initiative to improve the quality of health services since 1989 and the country has been making advances to increase service coverage but their efforts have not yielded the anticipated improvements in health status; the quality of health services has actually declined (Whittaker, Lynam, Burns \& Doyle, 1998).

Furthermore, increasing reports of irregularities and dissatisfied patients about the Ghanaian health system continue to surface in both electronic and print media in Namibia due to "....uneven health care quality, bad interpersonal relations and poor communication between health care providers and clients, mistreatment and missed-treatment" (McLaughlin \& Kaluzny, 2006). Similarly; Meyer, Carroll, Kutyla, Stepnick and Rybowski (2004) and Lynn, Baily, Bottrell, Jennings, Levine, Davidoff, Casarett, Corrigan, Fox, Wynia, Agich, O'Kane, Speroff, Schyve, Batalden, Tunis, Berlinger, Cronenwett, Fitzmaurice, Dubler and James (2007) point out that the "...United States health care system consists of preventable errors, unnecessary surgeries and inappropriate use of medications, procedures, misuse and underservices". In Namibia, the "...public health facilities are described by the public and health professionals to be below standards, overcrowding at outpatient department (OPD), long queues and long waiting times, as indicators of poor quality patient care" (MoHSS, 2013). These and other problems raise serious concerns, which necessitate immediate actions to adopt appropriate methods to improve health care services.

In context of quality management policy and positive improvement in the area of the HIV / AIDS programme in the MoHSS, there have not been comprehensive approaches to assist and empower health professionals with the necessary competencies to provide quality care at the health care facilities. At the time of this study, the focus of the health facilities was neither on systematic checks, safety controls, nor on significant activities on quality assurance training programmes. Other quality control mechanisms were scattered under different directorates.

On a policy framework, the Namibian Public Service Charter (2008) outlines the principles that guide the actions of the public servants. Despite efforts, there seems to be no significant or deliberate underlying structure to constantly insist on holistic quality care measures. Consequences would include poor performance, ineffective communication, inappropriate systems, as well as demotivated and dissatisfied staff members and patients. Extreme risks may include escalating diseases, social problems, and a fragile health care system. Although the MoHSS has endeavoured to reorganise and restructure some functions, no tangible results seem to focus on quality improvement at the public health care facilities. The main focus seems to be increasing the numbers of personnel to respond to emerging and re-emerging diseases and additional services. Countrywide, this approach has little or insignificant consideration for addressing quality care at the health care facilities. Often, public health care facilities are perceived as not performing and irresponsive to patient needs. Inappropriate methods, weaknesses, and negligence may result in a loss of lives due to ineffective practices and measures. "...[D]efficiencies in quality of care represent neither the failure of professional compassion nor necessarily a lack of resources rather a result from gaps in knowledge, inappropriate applications of available technology" (Murray \& Frenk, 2000), or the inability of organisations to change (Berwick, 1989). The absence of strong leadership and partnership may also jeopardize an effective and timely response to patients' needs. At the time of the study, there seemed to be no appreciation or persuasion of quality approaches to help leaders and employees address quality care problems at the health care facilities. Research presents several models applicable to the health care environment but few or nonspecific studies are focusing on quality improvement at public health care facilities in $\mathrm{Na}-$ mibia. Without a common understanding of quality improvement principles and the value of health care realities, patients' care might be compromised. A need exists, therefore, to (a) broaden the knowledge about quality improvement; (b) assist managers, employees, and patients to appreciate quality improvement models (c) apply practical tools or techniques to improve quality care; and (d) encourage active participation and involvement of all stakeholders in quality health care delivery. The main focus of this study was to develop a quality improvement training programme, which focused on a situation analysis to understand the approaches on QI and QI to improve health care and service delivery.

\section{Aim and objectives}

The aim of this study was to develop a quality improvement training programme for health professionals that focus on quality health care delivery at the health care facilities in Khomas, Erongo, Kunene and Omusati Regions. The focuses of this article is to describe the educational programme.

\section{Methodology}

In developing the quality improvement training programme for health professionals at the health care facilities, a five-phase approach was adopted (Meyer \& Van Niekerk, 2008), i.e. the preliminary phase, exploratory phase, design phase, development phase, and the evaluation of the programme. In developing the training programme, the five phases of programme development by Meyer and Van Niekerk (2008) were modified to support the programme development. The five phases formed the foundation for the objectives of this study, which facilitated the understanding of the research process and flow of information. The Preliminary phase was the first steps taken to submit documentation for approvals; hence it was regarded in this study as introduction to the situation analysis. These phases as described below, as follows

- Phase 1: Situational analysis;

- $\quad$ Phase 2: Conceptual framework;

- Phase 3: Developing of the training programme;

- Phase 4: Development of the guidelines for the implementation.

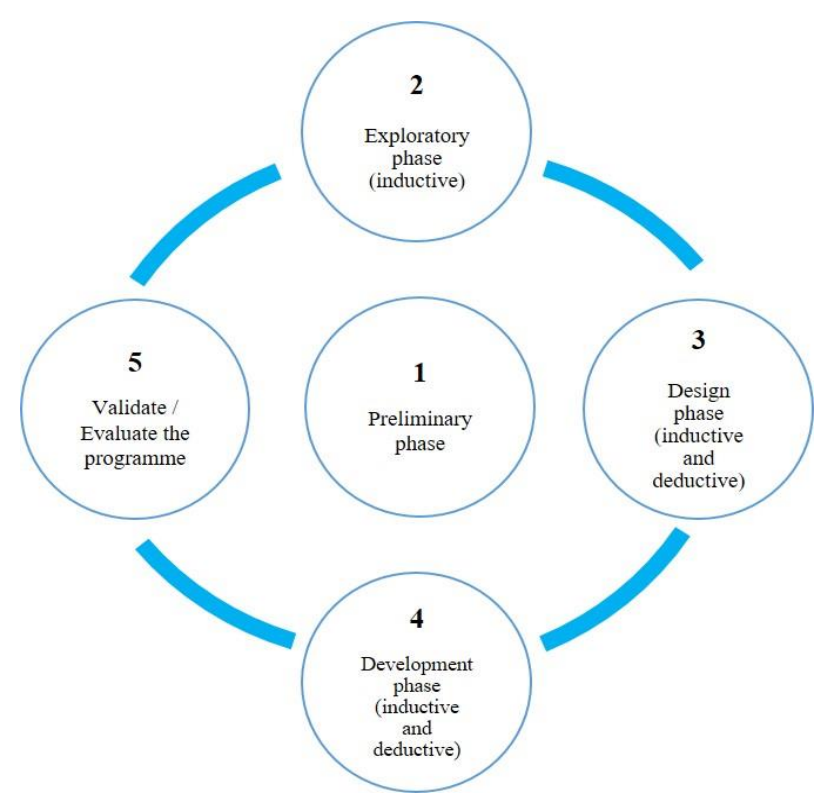

Fig. 1: Programme Development Process Steps of Meyer and Van Niekerk (2008). 
The development of the programme took certain research principles into account; namely the purpose / aim; the objectives and benefits, programme structure, programme process (facilitation process), educational approaches, evaluation / assessment techniques, implementation process, and the evaluation of the programme.

The training programme was validated by a team of expertise, managers, health professionals and stakeholders during a meeting to assess whether it was relevant to address the identified gaps in quality health care delivery in the health. Among the stakeholders who contributed to the programme review was Management at MoHSS head office, Health Professionals from Khomas region (WCH and Katutura Intermediate Hospital). The participants were given the opportunity to assess the programme based on the name, purpose, content, objectives proposed methods and learning approaches, as well as benefit of the training programme, as discussed below.

- The objectives and purpose of the training programme are clear and understandable.

- The learning methods, activities, and content are appropriate to meet the training needs of participants.

- The conceptual framework and learning theories are clearly explained.

- The stipulated benefits of the training programme are useful to the health care facilities and customers.

- The training programme will enable health professionals to improve efficiency and effectiveness in health care.

- Once, the training programme is implemented, there will be a significant improvement in quality health care delivery after attending training.

- Good methods had been described to enhance the training activities.

- There is a clear plan for disseminating the evaluation findings used to improve the efficiency of the training programme.

\section{Findings}

\subsection{Purpose / aim of the educational programme}

The purpose of this training programme was to empower health professionals with appropriate KSAs to improve health care and service delivery at the health care facilities. The focus of the programme was to enable health professionals to initiate and deliver exact quality improvement projects to address the identified challenges. The programme provided health professionals with learning approaches for their career and professional development to improve care and service delivery at the health care facilities. It empowered health professionals and managers to assume active roles and responsibilities in learning new principles and recen methods that were required to facilitate quality health care delivery at health care facilities. The programme promoted a quality culture and renewed commitment to meet the expectations and health needs of patients, as well as achieving the strategic objective: "MoHSS recognised the best public provider of quality health care in the country and beyond" by meeting the required quality standards of accreditation and certification. The programme further generated practical tools and methods for teaching and assessment to guide the process of implementing quality management in the MoHSS. It provided guidance to the MoHSS (health care facilities) about implementing the quality improvement training programme for health professionals. The findings from a situation analysis at the health care facilities indicated the need for quality improvement training with the view of enhancing knowledge, skills, abilities, and attitudes in quality health care delivery.

The content of the training programme was derived from five main themes, 17 sub-themes and the conceptual framework based on the situation analysis about challenges faced by the health care facilities. The five themes were:
- lack of implementation of policies and guidelines;

- inadequate resources

- lack of interpersonal relationships:

- inadequate understanding of quality assurance and quality improvement; and

- Inadequate research to provide evidence-based practice during treatment and patient care.

\subsubsection{The objectives of the educational programme}

The objectives of this training programme are to:

- Empower Health professional knowledge and skills in order to understand the process and standards for the implementation of available policies and guidelines in respect of QA and QI for quality health care delivery

- Enable the health professional to gain knowledge in terms of management and utilisation of available resources to enhance quality health care delivery;

- Empower the health professional with abilities to manage and improve interpersonal relationship in terms attitudes, communication, motivation, teamwork, and resistance change

- Enhance the important/significance of research and health information in health facilities for the purpose of evidence based practice.

\subsection{Benefits of the programme}

The quality improvement training programme had both short-term and long-term gains by contributing to the generally improved outcomes of health care that were informed by additional knowledge and skills. The programme had two main direct benefits to the participants in the MoHSS; namely enhancing care and service delivery, as well as a high satisfaction rate and happy families after receiving the best care.

\subsubsection{Benefits to the participants (recipients)}

The added benefits of participating in a credit bearing training unit contributed to the improvement of "...[t]heir lifelong learning in terms of credit recognition and transfer in learning and career pathways". It also inspired participants' interests in pursuing career development in the field of Quality Management Science for future promotion opportunities in QI or QA.

\subsubsection{Benefit to the society}

Meeting the expectations and health needs of patients is one of the prospects that each client and the Namibian government are yearning for and interest, hence the huge budget allocation to health care. A reduction in maternal and child health mortality would be one of the improved outcomes of well-trained and competent health professionals with quality health care delivery at heart.

\subsubsection{Profession (body of knowledge)}

The programme is the first of its kind in the MoHSS that covers the magnitude of work that has accumulated valuable and dense information through a research project that is adding value to the body of knowledge in the field of Quality Management Science and quality assurance to improve knowledge, skills, and abilities with the view of facilitating a quality health care delivery system at the health care facilities in the MoHSS.

\subsection{Programme structure / design}

The structure of the programme consists of the name of the programme, unit standards, quality assurance component (national qualification standard), outcomes standard, duration and successful completion of training, programme components, and content assessment. According to the Namibian Government Policy on 
Accreditation Regulations that is contained in the Qualifications Authority Act, 1996 (Act No. 29 of 1996) of Namibia, this programme belongs to a sub-category of short courses with qualifications that are registered at or below NQF level 5 and 6, or registered unit standards. This programme is offered at NQF levels 5 7 and is recognised by the NQA for certification of qualifications.

\subsection{Name of the programme}

This is a Quality Improvement Educational Programme for health professionals (QIEPH) in the MoHSS in Namibia.

\subsubsection{Unit standards}

"Unit standards specify learning and / or performance outcomes (what the candidate can do) and the required standard of knowledge and / or performance (how well the candidate can do it). Unit standards provide the basis for the design of assessment including audience, educators, trainers, assessors, candidates, and moderators" (New Zealand Qualification Authority, 2010). The unit standards of this programme would be considered for recognised certificate or diploma at NQF level 5, 6, or 7. The levels and required credits would be based on the NQA Guidelines (2006) for certification of qualifications, which states that a certificate has 40 NQF credits of which a minimum must be at or above the level of certification while a diploma has $120 \mathrm{NQF}$ credits of which a minimum of 72 must be at or above the level of certification. The level 6 diploma is equal to 360 credits offered at the institutions in Namibia, the SADC region, and outside the country if the international programmes are accredited or recognised by the NQA.

\subsubsection{Quality assured component (national qualification standard)}

The National Qualification Framework outlines the quality assurance components or criteria used for training programmes that are recognised, accredited, or awarding certification to participants. The quality improvement training programme contains unit standards that would be accredited for certification and recognition of qualifications. The training programme should be “...[d]elivered by competent providers and assessment leading to the award of the qualifications can be trusted" (Tuch, 2007). According to the NQA (2006), there are three important elements of quality assurance; i.e. validation of qualifications and / or standards, accreditation and audit of education and training institutions, and quality assurance of assessment that leads to awarding qualifications "...The use of unit standards in nationally recognised qualifications helps to ensure that: clear outcomes are recognised nationally and consistent standards apply to recognised outcomes; existing knowledge and skills are recognised and credited on the candidate's Record of Achievement (New Zealand Qualification Authority, 2010)

\subsubsection{Outcomes standard}

The outcomes standard of this training programme were the learning outcomes and descriptive measures to achieve the objectives, as described in this chapter. The outcomes include knowledge, skills, behaviour, attitudes, and values.

\subsubsection{Duration of training}

The programme would be offered in three formats based on the duration of either 7 days, 3 months, or a year; the short programme will be awarded with an attendance certificate while longterm training qualifies for a recognised certificate or diploma. The programme would be subdivided into three levels:

- Introduction to QI and QA principles and methods (7 days).

- Intermediate training programme focuses on an understanding and practical application of concepts, principles, and methods $(2-4$ months with follow-up and guiding activities to complete the required work).
- Advanced training programme focuses on application of concepts in real situations with an emphasis on problem solving and decision making, research methodology, as well as developing and monitoring quality indicators to improve patient care ( 4 months -1 year).

- Upon completing this training programme, the learner would either qualify for a certificate with relevant credit values, as per the NQA requirements.

\subsubsection{Completion of successful training}

The successful completion of the training programme would depend on the required achievement of the credits for a candidate to be awarded a certificate. The participants (learners) were assessed to demonstrate the abilities to develop, implement, collect, analyse, and monitor quality activities at the health care facilities. They should be able to plan, identify, and solve problems, as well as provide feedback on quality related issues at the health care facilities. At the end of the training programme, they should also exhibit positive attitudes towards clients and colleagues, and apply procedures and methods to improve patient care and treatment.

\subsection{Programme process (facilitation process)}

According to the Northwest Centre for Public Health (2012), different instructional methods are used in facilitation of learning and teaching. In this study, the following methods were used: Group work (role play, simulations, and games), individual work (selfassessments, evaluations, and writing), case scenarios, and paper / project assignments. A learner-centred and active learning approach was used to encourage and engage learners in activities that satisfied their needs. An understanding of health professionals constant involvement in problem solving situations and case management led to the use of case scenarios that gave groups an opportunity to reflect on their experiences and to analyse situations with the purpose of finding solutions. Participants would be asked to analyse and propose solutions on a case based on the activity objectives, for example a case study of a patient who developed severe abdominal pain and diarrhea.

\subsection{Educational approaches}

In this programme, the trainer or facilitator adopted an interactive style based on participants' experiences and previous knowledge. The principles of adult learning, such as Kolb's experiential learning advised the use of mixed methods in learning and assessment. These methods included role play, simulation, cooperative learning, reflection, visualisation, and case scenarios. These techniques responded to the adult learning needs of the participants by making the learning activities more stimulating, as emphasised by the proponents of adult learning. Sally and Russell (2006) emphasise that one of the reasons why adults engage in learning is to bring about meaningful change in skills, behaviour, attitudes, or knowledge level in the areas of their interests. Studies (Harris, 2007); Langer, 2002); Thorpe, 2004) argue that learning has shifted away from routine practice to a reflective professional practice, which encourages a student-centered approach in active learning that requires a good learner-educator relationship (Bergström, 2010).

\subsection{Programme components/ control}

The components of the training programme were derived from the five objectives of the study, which were subdivided into units and learning content (Tables 5.3 - 5.7). The programme consisted of five modules, which incorporated the tools and techniques to assess the learning outcomes and assessment criteria. The assessment methods of all activities in this programme are explained (Hanna and Dettmer, 2004) in Tables 5.3 - 5.7 below. During the situation analysis, participants shared that one of the factors mili- 
tating against QI and QA was a lack of knowledge, skills, and aptitudes in QI and QA. It included inadequate training on QI and QA policies and guidelines. The content are as follow:

Module 1: Policies and guidelines on QA and QI to facilitate quality health care

\section{Objective of the module:}

Understand the process and standards for the implementation of available policies and guidelines in respect of QA and QI for quality health care delivery

\section{Exit outcomes:}

- Recognise the institutional frameworks that guide the operations of quality health care delivery.

- Determine the important issues and priority needs for the policy development process for inclusion in QI and QA policy.

- Evaluate and critique the process of implementing QA and QI policies and guidelines to improve quality health care delivery.

- Develop policy points to be considered for improving quality health care delivery at health care facilities.

- Analyse the conceptual framework and dynamics surrounding QA and QI policies and guidelines.

- Identify and interpret the concept of QI and QA to facilitate quality health care delivery.

- Define the roles and responsibilities of stakeholders for implementing the Quality Management Policy to facilitate quality health care delivery at the health care facilities.

- Describe the key elements of implementing QA and QI policies at the health care facilities.

- Propose structures to facilitate quality health care delivery at the health care facilities.

- Apply procedures and standards correctly to deliver quality health care at the health care facilities.

\section{Learning content}

- Unit 1: Essential components of QA and QI policy

- Unit 2: Strategic planning

- Unit 3: Organisational structure

- Unit 4: Implementing a quality improvement programme

Module 2: Management and utilisation of resources to enhance quality health care delivery

\section{Objective of the module:}

Gain knowledge in terms of management and utilisation of available resources to enhance quality health care delivery

Exit outcomes

\section{Learning content:}

- Describe the management theories in relation to the health care context.

- Identify and critically discuss current human resource issues hampering quality health care delivery in a health care facility context.

- Describe the management theories that could be applied to enhance quality health care delivery in a health care facility context;

- Propose appropriate strategies that could be used by the health care facilities to attract and retain health professionals, and maximise adequate utilisation of human resources to improve patient care.

- Identify and critically discuss current issues and challenges in the field of human resource management obstructing quality health care delivery.

- Explain the purpose of change management.

- Identify and explain the roles and responsibilities of quality teams at health care facilities.
- Design a quality management and coordination plan for quality improvement at the health care facility.

- Describe types of organisational structures and their advantages to quality health care delivery.

- Propose an appropriate structure to facilitate quality health care delivery at the health care facilities.

- Establish a quality improvement team for adequate structure at health care facilities.

- Identify factors influencing an adequate structure at the health care facilities.

\section{Learning content:}

Unit 2.1: Material resources

Unit 2.2: Human Resources

Unit 2.3: Workload

Unit 2.4: Time management

Unit 2.5: Stress management

Module 3: Interpersonal relationships to facilitate quality health care delivery

\section{Exit outcomes}

- Acquire knowledge and abilities to manage and improve interpersonal relationship in terms attitudes, communication, motivation, teamwork, and resistance change

- Describe the process of communication.

- Discuss the role of communication in quality health care delivery.

- Compare and contrast the different types of interpersonal communication.

- Discuss the barriers to interpersonal communication and quality health care delivery.

- Propose strategies to enhance and improve communication for quality health care delivery.

- Identify factors influencing effective communication.

- Design methods for effective communication.

- Define the structure to facilitate quality health care delivery. Explain the importance of effective communication.

- Identify and explain the critical competencies required to improve communication between health care professionals and patients.

- Identify factors that would contribute to ineffective quality teams at the health care facilities.

- Design a communication plan to improve quality management and coordination of interpersonal relationships at the health care facilities.

- Identify factors influencing effective communication at the health care facility.

- Illustrate effective verbal and written communication skills.

- Based on a video recorded interaction with patients, learners should review and analyse their own behaviour. Learners assess and rate one another's performance on handling the case, as well as record and explain the reasons of the scoring.

\section{Learning content:}

Unit 3.1 Interpersonal communication

Unit 3.2: Managing group dynamics (attitudes and teamwork)

Unit 3.3: Quality culture

Unit 3.4: Conflict management

Module 4: Significance of research and information to facilitate quality health care

\section{Objective of the module:}

Acquire knowledge and attitudes in respect of the significance of research and information about quality health care delivery 


\section{Learning content:}

- Explain the purpose of conducting research to facilitate quality health care delivery. of the scoring

- Describe the research methodology and methods to be used to enhance quality health care delivery at health care facilities.

- Clarify the importance of evidence-based practice (EBP) to quality health care delivery.

- Define the fundamental ethical principles of research in relation to patient safety during care and treatment.

- Develop research topics to address challenges in quality health care delivery (collect, analyse, interpret, and report information) on quality health care.

- Explain how health care facilities are adhering to quality assurance standards and the improvement process to protect the rights of patients in health care.

- Define information management and information systems to enhance quality health care delivery.

- Distinguish between health information systems (HIS), human resource information systems (HRIS), and health management information systems (HMIS).

- Describe different types of information systems and technologies used to support quality health care delivery at health care facilities.

- Explain the types of tools used to facilitate quality health care delivery at the health care facilities.

- Describe the general functions, purposes, and benefits of health information systems in various health care settings.

- Describe the health care initiatives and significant developments that have influenced the evolution and adoption of health information systems.

- Compare / contrast different types of health information systems and how these systems are helping one to meet and respond to health care needs.

- Explain how electronic health records affect patient safety, quality care, efficiency, performance, and quality health care delivery in general (reporting, documentation, and implementation).

- Propose strategies to minimise barriers to using electronic health records.

\section{Learning content:}

Unit 4.1: Purpose of conducting research

Unit 4.2: Research knowledge for evidenced-based practice

Unit 4.3: Fundamental ethical principles of respect, beneficence, and justice in research to prevent harm to patients

Unit 4.4: Procedures and mechanisms for protecting rights in research

Unit 4.5: Types of information that facilitate quality health care delivery

Unit 4.6: Quality improvement tools for monitoring and evaluating quality health care delivery

Unit 4.7: Patient safety

\subsection{Facilitation technique}

The following facilitation techniques were used to enhance the learning experience.

Icebreakers: Icebreakers are discussion questions or activities used to help participants relax and ease them into a group meeting or learning situation (Dover, 2004). Icebreakers allow a student to become emotionally connected with the learning process and increases motivation (Kelly, 2004). Ice breakers are referred to as powerful thinking exercises that help motivate a group of learners to move from one stage to another during group development. "Ice breaker is a facilitation exercise intended to help a group to begin the process of forming themselves into a team, which are commonly presented as a game to 'warm up' the group by helping the members to get to know each other". According to research, ice breakers are an effective way of starting a training session or team-building event. As interactive and often fun sessions, ice breakers precede the main proceedings; they help people get to know one another and become committed to the purpose of the event. If such a session is well-designed and well-facilitated, it can really help get things off to a great start. By getting to know one another, getting to know the facilitators, and learning about the objectives of the event, people become more engaged in the proceedings and are more likely to contribute more effectively to successful outcomes. Ice breakers are used to assist a group with getting to know one another; integrate new members into a group; help young people feel comfortable in one another's company; encourage cooperation, teamwork, and good listening skills about people' ideas; develop social skills; build rapport with leaders; and create a conducive atmosphere for learning and participation (Knox, 2009).

Lectures: A lecture is one of the longstanding methods to present information used in higher institutions of learning. It is an actively facilitated presentation of information for about a 10- to 15-minute segment with interactive experiences, such as asking stimulating questions and class or small group discussions. During a lecturing method, various teaching aids are used; for example pictures, video clips, graphic organisers, and PowerPoint slide presentations to highlight the main topics.

Problem solving: Problems experienced by the health professionals at the health care facilities were common to their work environment; those problems were incorporated to create different scenarios and case studies that enabled learners apply creative and critical thinking. Brainstorming: This was used during group work as a technique to gather different thoughts on a topic during a group discussion. This method is used to generate various solutions to a problem by exploring different ways of approaching a situation. The method was mostly used in situations where the participants had to generate new ideas about unfamiliar topics.

Simulations: This technique is useful to display or assess practical ideas based on models to enable learners define concepts or acquire knowledge about observable or unobservable human or animal body parts to search for treatment regimens of certain health conditions. Simulations are also useful for assessment purposes, especially for assessing more advanced learning and attitude change (Smith \& Ragan, 1999). "The appropriate use of simulation in a professional education program [sic] allows students to hone their clinical skills without danger of harming the patient during the learning process" (Ziv, Wolpe, Small \& Glick, 2003). Given the demand for attending to patient needs; Begg, Ellaway, Dewhurst and Macleod (2007) have designed online virtual patient simulation called Labyrinth to assist learners with analysing cases and situations, synthesising knowledge from various learning experiences, and evaluating courses of action. According to Galloway (2009), simulation uses interactive approaches and models to present cases. Standardised patients, also known as simulated patients or actors, are live simulators that are utilised for teaching learners to conduct a physical assessment, take a patient history, communicate bad news, practice a psychiatric intervention, and even perform a pelvic or prostate examination (Doerr \& Murray, 2008). Partial task trainers are designed to replicate a part of a system or process. The learning objectives associated with partial task trainers are often task specific. Examples include intubation mannequins, IV practice arms, and machines involved in processes; such as surgery, resuscitation, and emergency scenarios. Advantages of these simulators include product sustainability, standardisation, portability, and skill specificity (Beaubien \& Baker, 2004a). Integrated simulators (human patient simulators) are whole body mannequins (adults, children, or infants) that are capable of responding to certain medications, chest compressions, needle decompression, chest tube placement, as well as other physiological interventions and subsequent responses. 
Debriefing: The formal, reflective stage in the simulation learning process is the debriefing process. Debriefing follows the actual simulation and serves to help learners clarify and integrate the simulation experience with previous knowledge (Decker, Sharon, Sportsman, Puetz, \& Billings, 2008). When debriefing is skilfully facilitated with a positive attitude and constructive criticism, learning is reinforced and the learner advances to transference, the next and final step in the simulation learning pyramid described by Doerr and Murray (2008).

Role play: Roles play is referred demonstrating or acting a prepared performance by the learners who assume the roles of the characters in a simulated situation in order to experience different points of view or positions. Actors portray patients with various ailments in mock examining rooms. Role play is a powerful technique that involves learners intermingling with their peers during the performance of specifically assigned activities.

Case scenarios: Cases scenarios are based on real situations about the conditions of patients that require treatment and care, which would be presented to students or participants to find solutions. Some of the skills learnt during case scenarios are problem solving, critical thinking, self-directed learning, and decision making.

Student presentations: Research shows peer teaching is an active learning strategy that results in significant gains in learning. Students practice professional roles and improve communication skills.

Debating:Debating is a structured way of exploring a range of views on an issue. It consists of a structured contest of argumentation when two opposing individuals or teams defend and attack a given proposition. In this study, the debating technique was used to:

- engage learners in a variety of activities that encouraged interaction and a deeper understanding of the learning content or curriculum;

- stimulate participants to consider not only the facts of a situation, but also the implications;

- inspire participants to think critically and strategically about both their own and their opponents' position;

- encourage engagement with and a commitment to a position, by its competitive nature;

- foster participants to develop interests and to engage in research;

- $\quad$ assist learners with developing good listening and oratory skills;

- helps educators to assess the quality of students' learning; and

- afford opportunities for peer reviews and to participate in evaluation.

Group discussions: Group discussions work usually involves groups of students formally working together on projects or assignments, though it may sometimes take place in formal classroom settings. When setting group work tasks, it is useful to consider student time and resources availability to meet the expected outcomes.

Plenary discussions and feedback: The Oxford Dictionary (2009) defines plenary discussions and feedback as a group of participants in a meeting or conference. Plenary discussions and feedback methods were used to summarise the sessions, topics, or lessons discussed in a group. The participants were divided into smaller groups to discuss an area or topic for a limited time and thereafter, each group was asked to select a representative to present their findings during the collective plenary meeting. Plenary discussions and feedback "...[h]elps [sic] pupils to focus on the most important rather than the most recent points learned and the progress they have made". Plenary discussions are useful learning techniques that assist learners and educators to:

- Summaries what has been learnt by underlining the most important points;

- Summarise the central themes, ideas, and vocabulary while emphasising what needs to be remembered;
- Generalise from examples generated earlier in the training event;

- Refocus the exercise, question learners, and rectify any remaining misunderstandings;

- make links to other work and next planned training events;

- Highlight not only what learners learn but how they have learnt;

- Underline the progress learners have made and remind them about their personal targets; and

- Set assignments that extend or consolidate class work and prepare for future training events.

\subsection{Evaluation /assessment technique}

Assessment refers to " $\mathrm{t}] \mathrm{he}$ process of gathering, interpreting, recording, and using information about learners' responses to an educational task" (Harlen, Gipps, Broadfoot, \& Nuttal, 1992). The criterion or standard of a unit assessment would be based on the study outcomes generated from the data analysis on the accounts and experiences of health professionals about situations obstructing the provision of quality health care. This also means that learners were assessed on prior knowledge or learning. Heritage (2007) identifies five components of assessing learners' prior learning based on the level of knowledge in a specific content area, understanding of concepts in the content area, the level of skills specific to the content area, attitudes they are developing, and the level of language proficiency.

The assessment of unit standards was highly interactive, participative, and practical because it was based on the experiences of learners within their work environment where the focus was more on problem solving and decision making to meet the expectations of patients at the health care facilities. In this study, a self-directed learning approach based on well-defined outcomes with some increasing levels of complexity was used to assess whether learners were progressing well.

\subsection{Implementation process}

In this study, certain steps were followed as part of the programme implementation process in the MoHSS. The implementation process of the training programme had adopted three phases, which were orientation, working phase, and termination (Neshuku, 2015). An introductory step was done for the orientation of the programme, the working step was done to introduce all the components of the programme, and the termination step enabled participants to evaluate and provide feedback on the training programme. The steps of implementing the training programme at the health care facilities in the MoHSS

Table 1: Steps of Introducing the Training Programme

\begin{tabular}{ll}
\hline Phases & Programme \\
\hline $\begin{array}{l}\text { Introductory } \\
\text { phase }\end{array}$ & $\begin{array}{l}\text { Introduction and welcoming remarks } \\
\text { Synopsis of the workshop } \\
\text { Discussing the purpose and objectives of the workshop } \\
\text { Setting up workshop ground rules } \\
\text { Determinants to: }\end{array}$ \\
- $\quad \begin{array}{l}\text { Address the challenges and constraints experienced } \\
\text { by health professionals in the implementation of } \\
\text { available policies and guidelines to enhance quality } \\
\text { health care delivery at the health care facilities. }\end{array}$ \\
$\begin{array}{l}\text { Equip health professionals and managers with the } \\
\text { right KSAs to understand and apply QI and QA prin- } \\
\text { ciples and methods to improve health care delivery. } \\
\text { phorking }\end{array}$ \\
$\begin{array}{l}\text { Establish effective mechanisms to improve interper- } \\
\text { sonal relationships among health professionals and } \\
\text { between clients to enhance quality health care deliv- } \\
\text { ery. } \\
\text { Promote research that generates evidence based prac- } \\
\text { tice about improving quality health care delivery. }\end{array}$ \\
$\begin{array}{l}\text { Termination } \\
\text { phase }\end{array}$ & $\begin{array}{l}\text { Evaluation and feedback on the training outcomes } \\
\text { Closing of the workshop }\end{array}$
\end{tabular}




\subsection{Evaluation process}

Evaluation is defined, as “...the comparison of actual project impacts against the agreed strategic plans, either formative (taking place during the life of a project with the intention of improving the strategy or summative (drawing learnings from a completed project that is no longer functioning". In this study, both summative and formative methods of evaluation were used to assess the process and outcomes of the learning content. Summative evaluation was used after the implementation to assess the impact and change in performance due to the effect of the training programme. A formative evaluation was conducted based on CDC Framework for Programme Evaluation in Public Health to evaluate the training programme at the health care facilities. CDC provided expertise to assist with developing guidelines and a quality management policy in the MoHSS.

The purpose of evaluation was to establish whether the goals and objectives of the training programme addressed the needs of participants to improve knowledge, skills, and aptitudes on QI and QI. It also assessed whether the programme contributed meaningfully to change and improve participants' performance after attending the training, which likely would result in improving the quality of patient care at the health care facilities.

The process of evaluating the programme had adopted four phases that were used to prepare for data collection and reporting of the. The phases were a desk review, field work, synthesis, and dissemination of the findings.

\subsection{Evaluation steps}

The steps for evaluating the training programme were adapted from the CDC framework for programme evaluation in public health and include: engage stakeholders; describe the programme needs; focus on the evaluation design; father credible evidence; present justification and Information sharing.

\section{Conclusion}

The rationale behind quality improvement is embedded in health care goals and inspired by the critical challenges that are frustrating quality health care delivery. These challenges include inadequate skills and competencies, insufficient understanding resulting in poor implementation of policies, ineffective interpersonal relationships, poor management of resources, insufficient research to generate accurate data, and a lack of monitoring and evaluation. These and many more challenges had prompted the need for developing the quality improvement training programme to empower health professionals with KSAs to enhance health (clinical) outcomes, improve efficiency of managerial and clinical processes, reduce cost and wastage due to mistakes and errors, and change the mind set by encouraging a culture of improvement that is committed to quality in the MoHSS.

Quality is linked to the systems or approaches in delivering care and services at the health care facilities. In order to make substantial improvement, health care facilities need to adopt a common understanding of principles, methods, and processes of quality health care delivery. Although health professionals are qualified in their respective domains and conscientious about providing quality care, their inability to develop quality measures and tools to make informed decisions stifles prompt quality care and service delivery. For instance, some of the methods like process mapping (Inputs, Processes, and Outputs / Outcomes) that organisations to improve quality are scanty in health care practices and systems. Health care facilities need to capture and monitor data about health indicators, such as maternal and child health and others, and should follow recognised quality measures or indicators.

\section{References}

[1] Ministry of Health and Social Services (2013). National Quality Management Policy. Windhoek. Namibia.

[2] Ministry of Health and Social Services (2013). Report of the Presidential Commission of Inquiry: Ministry of Health and Social Services, January 31, 2013. Windhoek.

[3] Ministry of Health and Social Services (2014). Final Report. Assessment of the National Quality Management System Used to Monitor and Improve Quality Health Service Provision in Hospitals and Health Centres in Namibia. Windhoek.

[4] World Health Organisation (2000). Design and implementation of health information systems. (Theo Lippeveld, Rainer Sauerborn, Claude Bodart, Eds.). Geneva. Retrieved June 5, 2015 from http://www.who.org.

[5] World Health Organisation (2000). Issues in health services delivery. Improving Provide Skills. Strategies for assisting health workers to modify and improve skill: Developing quality health care - a process of change. Discussion paper No.1. Retrieved August 20, 2014 from www.who.org.

[6] World Health Organisation (2006). HMN, Framework and standards for the development of country health information systems. The need for strong health information systems. www.who.int/entity/healthmetrics/documents (accessed, Oct. 9, 2014).

[7] World Health Organisation (2006). Improving health worker performance: in search of promising practices. Retrieved, June 12, 2013 from http://www.who.org.

[8] Whittaker, S., Lynam, F. P, Burns, D. \& Doyle, V. Introducing quality assurance to health service delivery - some approaches from South Africa, Ghana and Kenya. International journal for Quality in Health Care, 1998; Vol.10 (3). pp. 263-267. Country reports. Retrieved June 14, 2015 from http://intqhc.oxfordjournals.org/.

[9] McLaughlin, C. P. \& Kaluzny, A. D. (2006). Continuous Quality Improvement in Health Care. Theory, Implementations and Applications. (3rd ed.). Jones and Bartlett Publishers. United States of America.

[10] Meyer, J. A., Carroll, S.S., Kutyla, T., Stepnick, L. S., \& Rybowski, L. S. (2004). Hospital quality: ingredients for success-overview and lessons learned.

[11] Berwick, D. (1989). Continuous Improvement as an Ideal in Health Care. New England Journal of Medicine; Vol.320 (1): pp. 53-56. http://dx.doi.org/10.1056/NEJM198901053200110.

[12] Murray, C. J., \& Frenk, J. (2000). A Framework for Assessing the Performance of Health Systems. Bulletin of the World Health Organization. Vol. 78 (6): pp. 717-31.

[13] Meyer, S. \& Van Niekerk, S. (2008). Nurse educator in practice. Cape Town. Juta \& Co Ltd.

[14] Tuch, R. (2007). An Introductory Guide to National Qualification Framework. Concept and Practice Issues for Policy Makers. International Labour Organisation (ILO). Switzerland. Retrieve December 4, 2014 from http://www.ilo.org/publins.

[15] Offei, A., Sagoe, K., Owusu Acheaw, E., Doyle, V., \& Haran, D. (2010). Health Care Quality Assurance Manual for a Regional-Led, Institutional -based Quality Assurance Programme. . Eastern Regional Health

[16] Harris, M. J. (2011). Evaluating Public and Community Health Programs. (1st Edition). JohnWiley \& Sons. United States of America.

[17] Langer, A. M. (2002). Reflecting on practice: Using learning journals in higher education and continuing education. Teaching in Higher Education, Vol. 7(3), 337-351. http://dx.doi.org/10.1080/13562510220144824.

[18] Thorpe, K. (2004). Reflective learning journals: From concept to practice. Reflective practice, Vol. 5(3), 327-343. http://dx.doi.org/10.1080/1462394042000270655.

[19] Bergström, P. (2010). Process Based Assessment for Professional Learning in HigherEducation: Perspectives on the Student-Teacher Relationship. May 2010, Vol. 1(2). Retrieved February 12, 2013 from http://www.irrodl.org/index.php/erticle/view.

[20] Dover, K. H. (2004). Break the ice in classrooms and meetings. Icebreakers. Retrieved September 8, 2015 from http://adulted.about.com/cs/icebreakers/a/icebreaker.htm.

[21] Kelly, M. (2004). Warming up the classroom climate. The Ice Breaker. Retrieved September 82014 from http://712educators.about.com/cs/icebreakers/a/icebreakers.htm.

[22] Smith, P. and Ragan, T. (1999). Instructional design (2 ${ }^{\text {nd }}$ ed.). New York: John Wiley \& Sons, Inc. 
[23] Ziv, A., Wolpe, P., Small, S., \& Glick, S. (2003). Simulation-based medical education: An ethical imperative. Academic Medicine, 78(8), 783-788. http://dx.doi.org/10.1097/00001888-200308000$\underline{00006}$.

[24] Begg, M., Ellaway, R., Dewhurst, D. \& Macleod, H. (2007). Transforming Professional Healthcare Narratives into Structured GameInformed-Learning Activities. Innovate: Journal of Online Education, 3(6).

[25] Galloway, S. J., (2009). Simulation Techniques to Bridge the Gap Between. Novice and Competent Healthcare Professionals. OJIN The Online Journal of Issues in Nursing. Vol. 14(2). May 31, 2009.

[26] Doerr, H. \& Murray, W. (2008). How to build a successful simulation strategy: The simulation learning pyramid. In R. Kyle \& W. Murray (Eds.), Clinical Simulation: Operations, Engineering and Management (Chapt. 80). New York: Elsevier, Inc. http://dx.doi.org/10.1016/B978-012372531-8.50130-8.

[27] Beaubien, J., \& Baker, D. (2004b). The use of simulation for training teamwork skills in health. Vol.13 (i51-i56). Retrieved May 23, 2014 from http//:www.ncbi.nlm.nih.gov.

[28] Doerr, H. \& Murray, W. (2008). How to build a successful simulation strategy: The simulation learning pyramid. In R. Kyle \& W. Murray (Eds.), Clinical Simulation: Operations, Engineering and Management (Chapt. 80). New York: Elsevier, Inc. http://dx.doi.org/10.1016/B978-012372531-8.50130-8.

[29] Oxford Pocket Dictionary of Current English (2009). Oxford University Press. Retrieved 8 September 2015 from http://www.encyclopedia.com/doc/10999-plenary.html.

[30] Harlen, W., Gipps, C., Broadfoot, P. \& Nuttall, D. (1994). Assessment and the improvement of education. Chapter 34 in Moon, B. \& Mayes, A.S. Teaching and Learning in the Secondary School. London: Routledge / the Open University. http://www.tki.org.nz/r/maori_mainstream/tehiringa_e.php

[31] Heritage, M. (2007). Formative assessment: What do teachers need to know and do? Phi Delta Kappan. Vol. 89(2), pp. 140-145. http://dx.doi.org/10.1177/003172170708900210. 